\begin{tabular}{|l|l|}
\hline $\begin{array}{l}\text { ESCOLA DE COMUNICAÇÃO, } \\
\text { ARTES E DESIGN }\end{array}$ & $\begin{array}{l}\text { mídia, cultura e tecnologia } \\
\text { Fevista FAMECOS, Porto Alegre, v. 28, p. 1-13, jan.-dez. } 2021 \\
\text { PUCRS } \\
\text { FAMECOS }\end{array}$ \\
\hline e-ISSN: 1980-3729 | ISSN-L: 1415-0549 \\
\hline https://dx.doi.org/10.15448/1980-3729.2021.1.40142
\end{tabular}

MÍDIA E CULTURA

\title{
Por que o rádio brasileiro começou em Recife ${ }^{1}$
}

\author{
Why Brazilian radio started in Recife \\ Por qué comenzó la radio brasileña en Recife
}

\author{
Luiz Artur Ferraretto \\ orcid.org/0000-0001-9888-8834 \\ luiz.ferraretto@ufrgs.br
}

Recebido em: 15 fev. 2021

Aprovado em: 22 maio 2021.

Publicado em: 20 ago. 2021

\begin{abstract}
Resumo: Estudo historiográfico que reposiciona o Rádio Clube de Pernambuco, de Recife, como impulsionador da radiodifusão sonora no Brasil. Demonstra que a sua fundação institucionaliza um processo iniciado em meados da década de 1910 e que transforma experimentos de comunicação por ondas eletromagnéticas ponto-ponto - em especial, radiotelegrafia - em ponto-massa - na passagem da radiotelefonia para o meio rádio. Nesse sentido, descreve a atuação dos entusiastas pernambucanos, muitos dos quais com conhecimento técnico similar ao de seus congêneres dos Estados Unidos. Ao comprovar a importância de tal diferencial em relação a sociedades assemelhadas, demonstra o pioneirismo do grupo nordestino no desenvolvimento do que se conhece, então, como radiocultura.
\end{abstract} Palavras-chave: Radiocultura. Rádio Clube de Pernambuco. História do rádio.

Abstract: Historiographic study that repositions the Radio Clube de Pernambuco, from Recife, as a developer of broadcasting in Brazil. It demonstrates that its foundation institutionalizes a process begun in the mid-1910s and transforms communication experiments by point-point electromagnetic waves - in particular, radiotelegraphy - in mass-point - into the transition from radio telephony to radio as a kind of mass media communication. In this sense, it describes the performance of enthusiasts from Pernambuco, many of whom have technical knowledge similar to that of their congeners in the United States. By proving the importance of such differential in relation to similar societies, it demonstrates the pioneering of the northeastern group in the development of what is known, then, as radioculture.

Keywords: Radioculture. Radio Clube de Pernambuco. Radio history.

Resumen: Estudio historiográfico que reposiciona al Rádio Clube de Pernambuco, de Recife, como conductor de la radiodifusión sonora en Brasil. Demuestra que su fundación institucionaliza un proceso iniciado a mediados de la década de 1910 y transforma los experimentos de comunicación por ondas electromagnéticas punto-punto, en particular, la radiotelegrafia, en el punto-masa, en la transición de la telefonía sin hilos a la radio como medio de comunicación masiva. En este sentido, describe el desempeño de los entusiastas de Pernambuco, muchos de los cuales tienen conocimientos técnicos similares al de sus congéneres en los Estados Unidos. Al demostrar la importancia de tal diferencial en relación con sociedades similares, demuestra el pionerismo del grupo del noreste en el desarrollo de lo que se conoce, entonces, como radio cultura.

Palabras clave: Radio cultura. Rádio Clube de Pernambuco. Historia de la radio.

\footnotetext{
1 Uma primeira versão deste artigo foi apresentada no GP Rádio e Midia Sonora, $20^{\circ}$ Encontro dos Grupos de Pesquisa em Comunicação, evento componente do $43 .^{\circ}$ Congresso Brasileiro de Ciências da Comunicação. Esta reflexão não seria possível sem o auxilio das então estudantes de Jornalismo da Universidade Federal do Rio Grande do Sul Luísa Santini Januário, Nicolle Züge Marazini e Paloma da Silveira Fleck, além da jornalista Elisa Kopplin Ferraretto, que dedicaram tempo à pesquisa na Hemeroteca Digital Brasileira - Disponivel em: http://bndigital.bn.br/hemeroteca-digital. Acesso em 1 jul. 2021. É tributária de colaborações dos professores Luiz Maranhão Filho, da Faculdade Maurício de Nassau, de Recife (PE); Pedro Serico Vaz Filho, da Universidade Anhembi-Morumbi, de São Paulo (SP); e Guitherme Moreira Fernandes, da Universidade Federal do Recôncavo da Bahia, de Cachoeira (BA).

2 Universidade Federal do Rio Grande do Sul (UFRGS), Porto Alegre, RS, Brasil.
} 
Espécie de garoto-prodigio entre aqueles que se dedicam às transmissões por ondas eletromagnéticas, Oscar Dubeux Pinto assume em 1 de maio de 1925 o posto de chefe-operador da estação do Rádio Clube de Pernambuco, ${ }^{3}$ fundado em 6 de abril de 1919 e reorganizado quatro anos depois. ${ }^{4}$ Ao noticiar o fato, o Jornal Pequeno (RÁDIO..., 1925, p. 3), de Recife, estampa uma fotografia, na qual o jovem "aparece ao lado de um aparelho por ele construído, com o qual obteve, na recente Exposição Geral do Estado, ${ }^{5}$ medalha de prata e diploma de mérito".6 Pode-se dizer que Dubeux é, então, um arquétipo da maioria dos amadores da radiotelefonia e da radiotelegrafia, radio-escutas ou sem-filistas, idealistas que, desde a década anterior, operam estações próprias, não raro, às escondidas. Estimados em 1.200 até o final da década7 (CAPANEMA, 1929, p. 4), esses entusiastas têm papel fundamental no desenvolvimento, pela primeira vez no Brasil, e com boa chance de o ser também na América do Sul, da radiocultura, expressão daqueles tempos cuja análise demonstra a necessidade de posicionar a cidade de Recife como berço da radiodifusão no Brasil.

Recorre-se a tal ideia por se considerar o contexto e o processo de desenvolvimento do meio de comunicação em si mais importantes do que as persistentes polêmicas sobre a data de irradiações pioneiras. Considera-se também que radiocultura remete ao início da construção coletiva do rádio como instituição social, usando como referência as proposições de Eduardo Meditsch (2010, p. 204, grifo do autor) para a conceituação do meio:

Há mais de uma década, começamos a questionar o conceito de rádio atrelado a uma determinada tecnologia, procurando demonstrar que melhor do que isso seria pensar o rádio como uma instituição social, caracterizada por uma determinada proposta de uso social para um conjunto de tecnologias, cristalizada numa instituição. Consideramos hoje melhor ainda pensar esta instituição social como uma criação cultural, com suas leis próprias e sua forma especifica de mediação sociotécnica, numa analogia ao que propõe a ciência do jornalismo para definir o jornal. Assim como a existência de um jornal não se restringe ao calhamaço de papel impresso que foi publicado hoje, nem ao que foi publicado ontem, mas se vincula a uma ideia objetivada e apoiada numa instituição social, que permeia e supera a edição de cada dia, a existência de uma emissora de rádio em particular, e do rádio em geral como instituição, não pode mais ser atrelada à natureza dos equipamentos de transmissão e recepção utilizados para lhe dar vida, mas sim à especificidade do fluxo sonoro que proporciona e às relações socioculturais que a partir dele se estabelecem.

Fora isso, estabelecer um momento estático para origem de algo encobre a dinâmica histórica a perpassar o ali ocorrido. Para demonstrá-lo, insere-se a noção de radiocultura em periodização proposta anteriormente (FERRARETTO, 2012), perpassando a totalidade da fase de implantação ${ }^{8}$ do rádio e adentrando o início do período seguinte, o de difusão, ${ }^{9}$ quando, tratadas como negócio, as estações consolidam-se junto ao público. Torna-se indispensável repensar afirmações com base no senso comum e até em pesquisas de cunho científico, as quais marcam os discursos acadêmico, empresarial e jornalístico a respeito. São essas: a) a ideia de que Exposição Internacional do Rio de Janeiro é o início oficial do meio no país; e b) a de que a Rádio Sociedade do Rio de Janeiro tem prevalência em relação aos entusiastas nordestinos. Dá-se assim continuidade também a outras reflexões (FERRARETTO, 2013, 2018). No conjunto delas, trilha-se caminho idêntico ao indicado pela Carta

\footnotetext{
Como na época, usa-se o Rádio Clube, reforçando a ideia da entidade (MARANHÃO, 1984, p.5).

4 A reorganização do Rádio Clube de Pernambuco ocorre a partir de uma reunião realizada no dia 16 de outubro de 1923 (RÁDIO..., 1923, p. 1). 5 Evento organizado pelo governo de Pernambuco e realizado de 18 de outubro a 16 de novembro de 1924.

Este e os demais trechos citados de textos anteriores ao Acordo Ortográfico de 1990 tiveram sua grafia adaptada às normas atuais Foram corrigidos, ainda, erros na utilização da Lingua Portuguesa e/ou eventuais falhas de composição.

7 A informação é do reorganizador do Rádio Clube de Pernambuco, Oscar Pinto Moreira, sendo Oscar de Capanema o pseudônimo usado por ele para assinar artigos na imprensa.

8 Primeira fase da periodização proposta, estende-se do final da década de 1910 até a segunda metade dos anos 1930 e é marcada pela instalação das estações pioneiras, organizadas como associações (FERRARETTO, 2012, p. 8-10).

9 Segunda fase da periodização proposta, vai do início da década de 1930 até a segunda metade dos anos 1960 , caracterizando-se pelo predomínio de uma estratégia mercadológica de difusão, na qual o público é tomado como um todo ao qual se destina a programação formada, majoritariamente, por novelas, humorísticos e programas de auditório (FERRARETTO, 2012).
} 
de Natal (ALCAR,. 2019), documento no qual os pesquisadores reunidos durante o XII Encontro Nacional de História da Midia, da Associação Brasileira de Pesquisadores de História da Mídia (ALCAR), realizado na capital do Rio Grande do Norte, referendam o Rádio Clube de Pernambuco como o pioneiro da radiodifusão no país.

Não se pode considerar a demonstração realizada na abertura da Exposição Internacional do Rio de Janeiro, em 7 de setembro de 1922, como "a primeira transmissão oficial de rádio no Brasil" (SLAVIERO, 2012, p. A3), posição, de tempos em tempos, reiterada por entidades do setor e pela imprensa, caso do artigo comemorativo ao Dia do Rádio, assinado pelo então presidente da Associação Brasileira das Emissoras de Rádio e Televisão (Abert), Daniel Pimentel Slaviero, publicado em vários jornais e de onde se extraiu a assertiva. A palavra "oficial" remete à ideia de organização por parte das autoridades, algo que foi se construindo a partir da irradiação do discurso inaugural do presidente Epitácio Pessoa, dando início a uma série de demonstrações realizadas pelas estações SPC, da Westinghouse Electric and Manufacturing Company, instalada no Corcovado, e SPE, da Western Electric, na Praia Vermelha. $\mathrm{Na}$ realidade, o Governo Federal promoveu a exposição em si, mas as demonstrações - como as de tantos outros produtos e serviços - foram bancadas pelas empresas, tendo por objetivo buscar novos clientes para seus produtos, entre esses a União (FERRARETTO, 2013).

Essas ações das duas empresas dos Estados Unidos pouco se diferenciam de outras realizadas anteriormente, como a da Marconi's Wireless Telegraph Company, no Rio de Janeiro, em 1 de abril de 1920, conectando as instalações da Marinha, na ilha das Cobras, com o Palácio Rio Negro, local de veraneio da Presidência da República. Dias depois, a revista Fon-fon (A RADIOTELEFONIA.... 1920, p. 3) registra: "No Brasil, foi esta a primeira vez que se utilizou a radiotelefonia e, como tal, este acontecimento merecia ser devidamente assinalado". Oficial por oficial, a experiência da Marconi tem por trás a Marinha. Curiosamente, tanto em 1 de abril de 1920 quanto em 7 de setem- bro de 1922, a voz mais governamental transmitida é a do então presidente Epitácio Pessoa. Cabe observar ainda que, no início do mesmo ano da demonstração da Marconi, os jornais registram também outros testes realizados pela Marinha, por exemplo, os em que são usados os destroieres Pará (A TELEFONIA..., 1920, p. 3), Paraná (DIÁRIO DA MANHÃ, 5 mar. 1920, p. 3) e Sergipe (A RADIOTELEFONIA..., 1920, p. 3). Voltando mais no tempo, como já descrito (FERRARETTO, 2018, p. 151-153), ocorre, em 17 de abril de 1911, na costa da Bahia, a demonstração do chamado sistema Telefunken desenvolvido pelo consórcio Gesellschaft für drahtlose Telegraphie, a bordo do SMS von der Tann, cruzador-encouraçado alemão, de onde se transmite música captada pela Estação de Amaralina.

Fique claro, portanto, que as transmissões de 7 de setembro de 1922 não eram nem oficiais, nem pioneiras, embora, pela instalação de alto-falantes nos pavilhões da exposição e em função da distribuição de receptores a figuras de destaque na sociedade, possa se dizer que tenha sido a mais pública até aquele momento, referendando-se o afirmado em outra oportunidade (FERRARETTO, 2007, p. 93-94). Por outro lado, no atual estágio da pesquisa histórica, perderam sentido assertivas que relativizam as experiências realizadas pelo Rádio Clube de Pernambuco em prol de um caráter supostamente mais "regular" (FERRARETTO, 2007, p. 95) das transmissões da Rádio Sociedade do Rio de Janeiro, fundada em 20 de abril de 1923. Na sequência, sem diminuir - papel desse grupo de idealistas liderado por Edgard Roquette-Pinto, vai se demonstrar que o ocorrido na então capital federal faz parte de um processo maior cujo início remonta a meados da década de 1910 e tem por local a cidade de Recife.

Faz-se necessário compreender, no seu contexto de época, o significado do termo cultura e do seu emprego em relação ao rádio. Antes, é preciso demarcar que rádio, a palavra em si, possui um sentido diverso, nas décadas iniciais do século 20, daquele a identificar, logo em seguida, o meio responsável pela transmissão de mensagens sonoras por ondas eletromagnéticas 
de uma estação para diversos pontos receptores. Como demonstrado em reflexão anterior (FERRARETTO, 2012), radiotelegrafia, radiotelefonia e radiocomunicação ${ }^{10}$ confundem-se da década de 1880 até os anos $1920^{11}$ nos paises de fala inglesa, com reflexos evidentes no Brasil, sendo denominadas, genericamente, de wireless - em português, sem fio. Conforme o Oxford English Dictionary (2009), o prefixo radio- vai formar essas palavras substituindo, a partir de 1881, a expressão wireless e adquirindo, na década de 1900, significado independente como sinônimo dessas, dos aparelhos empregados e mesmo da mensagem especíica transmitida através de telegrafia ou de telefonia por ondas eletromagnéticas. Cabe recordar que, para identificar o meio de comunicação específico, a mesma fonte registra a disseminação do uso de radio somente a partir de 1922, embora Lee De Forest, um dos cientistas pioneiros deste campo, já a utilize, com sentido semelhante, em um artigo publicado no ano de 1907.

\section{Do sem fio à radiocultura}

Em uma cidade que deve a sua denominação à "linha de arrecifes que formava um ancoradouro" (SILVESTRIN; NOLL; JACKS, 2016, p. 155), a posição geográfica e a existência de um porto a conectar o Nordeste com o exterior e com o Sudeste servem de provável explicação para a proximidade dos amadores de Recife com a tecnologia da comunicação por ondas eletromagnéticas. Já nos anos 1910, mensagens em Código Morse ou de voz são essenciais à economia de Pernambuco focada na exportação de açúcar e dependente, a partir dos armazéns e do cais, da informação sobre a chegada e a saída de navios, além do contato com tais embarcações. Não por acaso, ao longo da década, a Societé de Construction du Port de Pernambuco encarrega-se da modernização da estrutura existente, que volta ao controle do governo estadual em 10 de dezembro de 1920 (PORTO DO RECIFE, [200-?]). Comércio exterior, indústria açucareira, marinha mercante, novo cais e armazéns recém-construídos permitem supor também tanto a necessidade de uma tecnologia de comunicação sem fios quanto à possibilidade de acesso a informações sobre essa provenientes de outros países, que chegam na forma de publicações via postal ou mesmo por meio de passageiros e tripulantes.

Já no início dos anos 1910, na imprensa local, artigos de entusiastas demonstram familiaridade com os avanços dessas tecnologias no exterior. É o caso de "A telegrafia sem fios no Brasil" (MELO, 1910, p. 1), assinado por Mário Melo, ${ }^{12}$ que alude a "uma revista norte-americana" sem identificá-la e chega a listar obras de referência nas quais se baseia. Entre outros, são citados os livros $L a$ télégraphie sans fil, l'œuure de Marconi, de Emilio Guarini; La télégraphie sans fil, de Henry de Graffigny; e Tratado prático de eletricidade, de Alfredo Soulier. Em tom algo eufórico, outro texto sem identificação de autoria (A TELEFONIA..., 1914, p. 9) prevê: "É de se esperar que a radiotelefonia será, dentro de pouco tempo, empregada em todas as comunicações transoceânicas". A proximidade com a literatura especializada também aparece na circulação em Recife de publicações como a Revista Maritima Brasileira, da Marinha de guerra, trazendo, por vezes, textos técnicos sobre o sem fio, caso de sua edição de março de 1910 (PUBLICAÇÕES, 1910, p. 1); ou como o Year Book of Wireless Telegraphy and Telephony, anuário para 1915, "um luxuoso volume encadernado, com cerca de 800 páginas" enviado pelo seu editor para o jornal A Provincia (PUBLICAÇÕES, 1915, p. 1).

Há, ainda, reproduções de entrevistas com Guglielmo Marconi (O GRANDE..., 1910, p. 1) e de reportagens a respeito de suas invenções e

\footnotetext{
10 Expressão que identifica as comunicações via ondas eletromagnéticas de uso militar e naval.

11 Mesmo em 1929, a palavra "radiotelefonia" ainda é usada como sinônimo de "rádio". Preocupados com o futuro do Rádio Clube de Pernambuco, associados fazem publicar nos jornais textos nos quais, por exemplo, afirmam: "Parece incrivel que, enquanto a radiotelefonia prospera em todo o universo, enquanto, mesmo no Brasil, se multiplique em estações, como no Rio de Janeiro, em São Paulo, no Rio Grande do Sul, na Bahia, no Ceará e no Pará, tenha de sucumbir por inanição a mais antiga sociedade de rádio da América do Sul" (RADIOELETRICIDADE, 7 jun. 1929, p. 3).

12 O mesmo que, em 10 de outubro de 1923, aparece como um dos entusiastas a subscrever a ata da reunião de reorganização do Rádio Clube de Pernambuco (RÁDIO..., 18 out. 1923, p. 1.).
} 
empresas (TORQUET, 1911, p. 3), além de notícias acompanhando a instalação de estações radiotelegráficas, como a da ilha de Fernando de Noronha (LOGO..., 1913, p. 3), ou sobre conferências a respeito de radiotelefonia, caso da proferida pelo telegrafista José Diniz Barreto (CONFERÊNCIAS, 1914, p. 11). Cabe lembrar ainda que um dos poucos registros localizáveis na Hemeroteca Digital Brasileira relacionado à já citada transmissão do SMS von der Tann é da imprensa pernambucana. "Nas experiências de radiotelefonia", registra o Jornal do Recife (NAS EXPERIÊNCIAS..., 1911, p. 1), "foram ouvidas distintamente melodias, árias e canções executadas a bordo". Embora sucinta, essa descrição é a mais completa a respeito do ocorrido e, talvez, não por acaso seja de um periódico daquela capital nordestina.

Fora isso, com chances ou não de estar relacionada ao deslumbramento frente ao sem fio, o Diário de Pernambuco (DIÁRIO..., 1914, p. 5) publica uma nota, curiosa pela inexistência de mais detalhes a respeito. Trata-se, no entanto, de mais um indicio sobre as particularidades do ambiente da região, mesmo que a entidade referida apenas usasse - com propriedade ou por blague - a palavra "rádio":

Na vizinha cidade de Olinda, segundo nos informam, vai ser criada uma sociedade recreativa por alguns cavalheiros ali veraneando.

O Rádio Clube, que tal é o nome da aludida sociedade, é composto exclusivamente de pessoas de distinção social, tendo por fim proporcionar às familias olindenses, durante a estação, diversões variadas (DIÁRIO..., 1914, p. 5).

Neste contexto de curiosidade em relação à transmissão de mensagens por ondas eletromagnéticas, é preciso tomar a palavra "cultura" como o fazem então tais entusiastas para formar a expressão "radiocultura". O Dicionário prático ilustrado, editado sob a direção de Jayme de Séguier, registra na época:

Cultura, s. f, (lat. cultura). Ato, modo ou efeito de cultivar: a cultura do cacau tem enriquecido a ilha de S. Tomé. Utilização industrial de certos produtos naturais: a cultura dos bichos da seda.
Estudo: a cultura da poesia. Elegância, esmero: a cultura da linguagem. Adiantamento, civilização: a Alemanha é um pais de grande cultura (DICIONÁRIO..., 1910. p. 291, grifo do original).

Portanto, por aproximação, a expressão "radiocultura" remete ao cultivo do rádio, ao seu estudo e à sua divulgação, incluindo ou não práticas de produção, transmissão e/ou recepção de conteúdo, utilizando um bem natural, as ondas eletromagnéticas. É algo em processo, um rádio em transição que deixa, em termos de morfologia, de ser prefixo e vai abandonando a telegrafia e a telefonia para se transformar em algo novo e independente, um cultivo que metamorfoseia a entidade em emissora. Fique claro que se diferencia da difusão de cultura, aquela tomada como um ideal de civilização.

Em alguns dos chamamentos publicados nos jornais para que o Rádio Clube seja fundado, fica clara a existência de um referencial estrangeiro de modernidade, emanando da América do Norte: "Um grupo de rapazes que se dedicam aos estudos da eletricidade e de suas manifestações, em boa hora, resolveu, a exemplo dos Estados Unidos, constituir uma sociedade para incentivar o estudo da radiografia ${ }^{13}$ entre nós" (RÁDIO..., 1919. p. 3). Há o desejo de emular práticas como a criação da Radio League of America, fundada em 1915, em Nova lorque. Isso aparece claramente nos Estatutos e regulamentos das estações (RÁDIO CLUBE DE PERNAMBUCO, 1919), aprovados pelos associados em assembleia realizada na Escola Superior de Eletricidade, no dia 27 de abril de 1919. Uma comparação desse documento com as regras estabelecidas pela Radio League of America (THE RADIO..., 1915. p. 381-384) demonstra, com clareza, semelhança entre os objetivos dos amadores pernambucanos e de seus colegas norte-americanos. O estatuto do Rádio Clube é claro a respeito da promoção de práticas que se confundem na época:

Art. $2^{\circ}$ - O fim do Rádio Clube é defender os interesses da numerosa classe de radioamadores, promovendo ao mesmo tempo o seu aperfeiçoamento técnico, sobre as seguintes bases:

${ }_{13}$ Expressão que, talvez por desconhecimento ou pelas confusões de então, aparece, por vezes, como sinônimo das tecnologias relacionadas à comunicação por ondas eletromagnéticas. 
A - Vulgarizar, entre os seus associados, a telegrafia sem fio e outras aplicações das ondas hertzianas, tais como a telefonia sem fio, a radiodinâmica ${ }^{14}$ etc., tornando-os, por esta forma, uteis à sua Pátria, pois a TSF ${ }^{15}$ tem influente papel nos exércitos e marinhas das principais potências

B - Trabalhar junto aos poderes públicos do país a fim de ser conseguida uma lei, semelhante à existente nos Estados Unidos da América, regulando as estações experimentais e as de amadores.

C- Solicitar da imprensa local, da Capital Federal e de todos os demais estados da União, inteiro apoio às ideias acima, tornando-se, portanto, mais fácil a realização do nosso desideratum.

D - A montagem de uma estação experimental de primeira ordem, onde possam ser estudados e aperfeiçoados os meios de transmissão sem fios do pensamento humano, já por sinais convencionais como os atualmente em uso na telegrafia, já pela telefonia.

E - Conseguir dos amadores dos demais estados da federação a fundação de sociedades congêneres, as quais, sob a mesma denominação e programa, serão oportunamente coligadas em uma única associação, sob o título de Rádio Liga Brasileira. (RÁDIO CLUBE DE PERNAMBUCO, 1919, p. 3-5).

A referência à necessidade de uma legislação especifica evoca situações vivenciadas em 1914. quando, sob o impacto da Grande Guerra, os amadores sofrem dura fiscalização por parte do Governo Federal. De certo modo, aproxima-se também do regramento da Radio League of America a explicitar a obediência a todas as regras e regulamentações do Wireless Act of 1912 (THE RADIO..., 1915, p. 383), documento legal que obrigava à obtenção de uma licença por parte dos amadores estadunidenses e proibia irradiações amadoras em faixas destinadas a comunicações comerciais ou militares. A preocupação aparece com mais nitidez nas seis determinações sobre transmissão e nas três a respeito de recepção que compõem o Regulamento das estações de amadores (RÁDIO CLUBE DE PERNAMBUCO, 1919, p. 14-16). Nessa parte do documento, fica claro que o grupo original de Recife ainda tem proximidade com a telegrafia sem fio: "O código oficial será o continental ${ }^{16}$ e não será permitido, sob pretexto algum, o uso de códigos secretos" (RÁDIO CLUBE DE PERNAMBUCO, 1919, p. 15).

Sobre o desenvolvimento inicial do meio, Humberto Sodré Pinto (2013) oferece importante contribuição, em especial por concentrar o foco na importância do Rádio Clube de Pernambuco. O autor divide a história do meio rádio em três períodos:

a) radiocuriosidade, "época em que os curiosos da especialidade se reuniam para tomar conhecimento da nova técnica, tentando com ela identificar-se, estudá-la, aprendê-la e iniciar-se nas recepções e transmissões radioelétricas" (PINTO, 2013, p. 203);

b) radiocontribuição, "quando foram organizadas as sociedades civis", isto é, "uma organização denominada sociedade ou clube, com estatutos e regulamentos aprovados e sedes instaladas, passando então a serem cobradas mensalidades" (PINTO, 2013, p. 204);

c) rádio comercial, "o último e atual estágio alcançado [...], abrangendo mais de 95\% das emissoras em funcionamento, que se mantêm exclusivamente pelas receitas de publicidade" (PINTO, 2013, p. 204-205). Para o escopo desta reflexão, interessam as duas primeiras.

Pela leitura dos estatutos e pela consulta aos jornais de época, vai se divergir em certa medida do exposto por Sodré Pinto. Fique claro que não se está diminuindo o depoimento publicado originalmente no ano de 1965 em Comunicações \& Problemas, pioneira revista científica criada por Luiz Beltrão no Instituto de Ciências da Informação da Universidade Católica de Pernambuco. Afinal, trata-se do primeiro texto a reivindicar, no meio acadêmico, um papel relevante para o grupo de Recife. Em um raciocínio interessante considerando os dados então disponiveis, Sodré Pinto (2013, p. 206) aponta o Rádio Clube de Pernambuco como o pioneiro do momento

4 Controle de mecanismos por ondas eletromagnéticas (MIESSNER, 1916).

15 Telegrafia ou telefonia sem fio. Na época, as duas formas confundem-se no uso dado à sigla.

16 Forma aperfeiçoada do Código Morse criada na Europa e, por ser mais simples do que a original, adotada oficialmente pela União Telegráfica Internacional em 1912 
inicial, o de radiocuriosidade, papel que atribui à Rádio Sociedade do Rio de Janeiro no periodo seguinte, o de radiocontribuição. Na realidade, a grande diferença entre as duas entidades não se relaciona às suas formas de estruturação. Afinal, já nos estatutos do Rádio Clube, o artigo 6. ${ }^{\circ}$ estabelece: "Fica adotada a joia de $5 \$ 000$ e a mensalidade de $2 \$ 000^{17}$, para os sócios efetivos. Os fundadores estão isentos da contribuição de joia, sendo, porém, obrigados ao pagamento das mensalidades" (RÁDIO CLUBE DE PERNAMBUCO, 1919, p. 5-6). Conforme Maria Elvira Bonavita Federico (1982, p. 38), usando como base publicações da Rádio Sociedade, a entidade carioca chega a arrecadar $33.400 \$ 000^{18} \mathrm{em}$ mensalidades no ano de 1923. A diferença entre ambas está mais no contato prévio de seus idealizadores com o sem fio e no que havia disponivel em termos de possibilidades para essa tecnologia à época das fundações de tais associações.

Os indícios apontam, ainda, para a troca de mensagens de telegrafia sem fio entre entusiastas desde antes do Rádio Clube ser fundado (RADIOTELEGRAFIA, 1915, p. 1). É um processo que, ao ir incorporando o som, faz a passagem para a radiotelefonia e, dessa última, para o rádio como meio de comunicação ponto-massa. De que processo se trata? Do indicado, conforme o contexto de época, pela palavra "radiocultura", algo que se inicia em Recife e do qual associações posteriores fazem parte como continuadoras, caso da Rádio Sociedade do Rio de Janeiro. Pode-se dizer que se concretiza completamente apenas após a regulamentação da publicidade pelo decreto n. 21.111, de 1 de março de 1932, a partir do qual o cultivo do rádio consolida-se sob a crescente hegemonia das emissoras comerciais. Em Recife, como vai se descrever em seguida, tal processo é tributário da ação de quatro pioneiros cujas trajetórias entrelaçam-se com a do Rádio Clube de Pernambuco: Augusto Pereira, Oscar Dubeux Pinto, Oscar Moreira Pinto e Tito Xavier. Pelos três últimos, passam também as primeiras transmissões realmente radiofônicas de Recife, embora não seja possivel precisar a data em que ocorreram, sua existência baseie-se em relatos orais e nenhum de seus protagonistas fizesse parte do grupo fundador do Rádio Clube de Pernambuco.

\section{Do rádio como prefixo à rádio com prefixo}

É Augusto Pereira quem dá o passo inicial no desenvolvimento da radiocultura no Brasil. Se há a necessidade de um documento a atestar o seu papel no desencadear do processo, esse aparece na forma de uma carta, com data de 17 de abril de 1915 e publicada no jornal A Provincia (RADIOTELEGRAFIA 1915, p. 1), em meio à constante fiscalização e apreensão de estações amadoras por parte do Governo Federal em função da neutralidade brasileira na Grande Guerra iniciada no ano anterior. Nela, esse entusiasta defende a elaboração de uma lei semelhante à existente nos Estados Unidos ou na Inglaterra, que, após o conflito, regule as estações dos amadores do sem fio, já então contando mais de uma dezena apenas em Recife.

A respeito dessa época e citando a mesma carta, Oscar Dubeux Pinto (1984) dá conta de que, antes da Grande Guerra de 1914-1918, "já havia em Pernambuco amadores de radiotelegrafia que se intercomunicavam utilizando aparelhos construidos por eles próprios". Conforme essa mesma fonte, com o fim do conflito, Augusto Pereira mantém contato com amadores até de outras regiões, sempre com um objetivo:

Agora que não havia mais guerra, os amadores, já em número maior, tratavam de se congregar numa associação que defendesse seus interesses, não somente no campo da radiotelegrafia, como também na radiotelefonia, ou seja, a transmissão da voz e da música pelo rádio (PINTO, 1984).

Em seu relato, Dubeux Pinto oferece um roteiro para a compreensão dos primeiros momentos do Rádio Clube. Como descrito, Augusto Pereira envia três correspondências, todas publicadas em edições da revista Radio Amateur News, órgão oficial dos sem-filistas norte-americanos. Na primeira, apresenta a entidade brasileira e

7 Respectivamente, cinco mil-réis e dois mil-réis, a moeda da época.

18 Na moeda da época, 33 contos e 400 mil-réis 
solicita cópias da legislação dos Estados Unidos a respeito e dos estatutos da Radio League of America, além de indicações de fornecedores de equipamentos (PEREIRA, 1919, p. 69). Nas duas cartas subsequentes, apresenta o secretário do Rádio Clube, Alexandre Braga, pedindo que the seja facilitado o acesso às estações de amadores durante sua visita aos Estados Unidos (PEREIRA, 1919, p. 126). Com referência à revista da Radio League, Dubeux Pinto (1984) registra, ainda, a publicação de uma fotografia enviada por Augusto Pereira, na qual aparece "um pequeno transmissor de telefonia de 5 watts". Na estação-laboratório, é possivel ver um bocal - o microfone - em um dos equipamentos, comprovando a informação de que se trata de um aparelho apto à transmissão da voz (THE AMATEUR..., 1924, p. 680).

Pelos dados existentes, não é possivel afirmar se esse equipamento chega a ser usado antes das transmissões realizadas pela Rádio Sociedade do Rio de Janeiro a partir de 1 de maio de 1923 (FERRARETTO, 2013, p. 17-20). No entanto, transcrito por Dubeux Pinto (1984), o depoimento do próprio Augusto Pereira dá pistas a respeito:

[...] usávamos os nossos transmissores e receptores de telegrafia e telefonia home made e, aos poucos, impondo-nos à boa amizade dos profissionais, ofereciamos para escuta aparelhos feitos por nós, melhores e mais eficientes do que os existentes nas estações de TSF, já obsoletos, e, assim, eles iam esquecendo a nossa clandestinidade. Convém esclarecer não ter iniciado a mania em 1919. Antes de 1910 eu já mexia com o éter (grifo do autor).

No mesmo relato, Pereira - "no ocaso da sua vida, esquecido, magoado, amargurado" (PINTO, 1984) - relaciona a fundação da entidade com a ideia de radiocultura:

O Rádio Clube de Pernambuco foi a primeira entidade de radiocultura fundada no Brasil, quiçá na América do Sul. [...] Devo dizer que as minhas atividades nessa ciência vinham de longe, podendo afirmar que antes de 1910. Havia uma mentalidade contrária a nossa mania. Éramos perseguidos, os nossos aparelhos apreendidos pela policia etc., porque dizia-se tratar-se de clandestinos no setor de comunicações radioelétricas.
Essas perseguições, segundo corria entre nós, originava-se, principalmente, da Companhia Marconi ${ }^{19}$, o que não posso afirmar.

Leitor constante de revistas científicas americanas e francesas, imaginei ser possivel adotar no Brasil a conduta americana na organização de radio clubs semelhantes aos que pululavam nos Estados Unidos.

Reuni os maníacos, discutimos sobre o assunto e resolvemos fundar a nossa própria associação, para nos livrarmos das perseguições das companhias privadas e do próprio governo (PEREIRA apud PINTO, 1984, grifo do autor).

Impulsionando o desenvolvimento da radiocultura, o foco dos pioneiros de Pernambuco começa a mudar depois de 1920 com o início das transmissões da KDKA, estação de rádio instalada em Pittsburgh, nos Estados Unidos, e operada pela Westinghouse. A mais antiga referência à escuta da emissora por pessoas ligadas ao Rádio Clube de Pernambuco localizada na Hemeroteca Digital Brasileira aparece no início de 1924 e, mesmo assim, citando algo ocorrido em São Paulo, no dia 17 de janeiro, durante uma visita àquela cidade de Carlos Lacombe (RÁDIO, 1924, p. 7-8), engenheiro que, pouco antes, participa da reorganização da entidade recifense (CONVOCAÇÃO, 1923, p. 6). No entanto, é de se supor algum conhecimento anterior a respeito de tais irradiações, uma vez que, desde antes da fundação do Rádio Clube, os entusiastas mantêm contato com publicações e amadores dos Estados Unidos. De fato, nos primeiros anos da década, o Rádio Clube enfrenta dificuldades para se manter - o que pode explicar uma ausência de registros a respeito do sem fio e de seus cultores -, acabando por receber, em 1923, quando de sua reestruturação, o apoio de um dos principais usineiros de então, como descreve Augusto Pereira (apud PINTO, 1984):

[...] como um enviado do céu, surge a figura de João Cardoso Ayres Filho. Este, de volta de uma de suas costumeiras viagens ao estrangeiro e tendo observado o valor e a utilidade patriótica da nossa associação, propôs-nos a sua reorganização, disposto a empregar o seu capital e de vários amigos influentes. 
Nos registros da imprensa de meados da década de 1920 sobre a escuta da KDKA, em Recife, surge com frequência o nome de Tito Xavier, "apontado como a maior autoridade em radiotelefonia em Pernambuco" (RADIOTELEFONIA, 1925, p. 1). Identificado como engenheiro ao assumir, em 1918, o cargo de chefe do Serviço de Eletricidade do porto de Pernambuco (ENGENHEIRO..., 1918, p. 1), participa, na década seguinte, da reorganização do Rádio Clube e monta, em paralelo, uma oficina especializada na qual conserta equipamentos e comercializa receptores, tornando-se, conforme a seção "Radiotelefonia", publicada no Diário de Pernambuco, "o principal fabricante de aparelhos de ondas curtas para as irradiações de Pittsburgh" (RADIOTELEFONIA, 1925, p. 2). A respeito de Tito Xavier e dando como fonte Oscar Dubeux Pinto, o jornalista Antônio Camelo (CAMELO, 1984, p. 3) registra em texto alusivo aos 65 anos do Rádio Clube:

Na fase de reorganização da Rádio Clube, em 1923/24, os possuidores de aparelhos de recepção ainda puderam escutar transmissões de voz e música feitas por uma estação clandestina. Os próprios dirigentes da Rádio Clube, usando processos de radiogoniometria $^{20}$, puderam localizar a estação, em Casa Amarela ${ }^{21}$, descobrindo então seu proprietário. Era o também pioneiro Tito Xavier, competente técnico e fabricante da aparelhagem de rádio. Ele fechou sua emissora fantasma e passou a integrar a diretoria técnica da rádio.

No entanto, a respeito de tais irradiações, o próprio Dubeux Pinto (1984) lamentaria: "Não foi encontrada qualquer informação referente à data em que isso aconteceu, infelizmente". Essa falta de registro - explicada pelas proibições legais impostas aos amadores - acompanha outras experiências, também dependentes da memória e de relatos orais, que poderiam ser apontadas como as primeiras irradiações. É o caso envolvendo João Cardoso Ayres Filho: "Ainda em 1923, antes de reorganizada, a Rádio Clube fez transmissões com equipamentos instalados na rua Benfica, no palacete residencial de João
Cardoso Ayres, que depois veio a ser presidente da emissora. O programa chegou a ser ouvido em Jaboatão22" (CAMELO, 1984, p. 3).

A reorganização do Rádio Clube passa por Oscar Moreira Pinto, um jovem telegrafista que, por problemas de saúde, deixou a marinha mercante e, ao chegar em Recife, "tomou conhecimento da iniciativa dos pioneiros pernambucanos em radiotelefonia" (ALCIDES, 1997, p. 52). Sobre o seu envolvimento diretamente com irradiações sonoras, há várias versões. Algumas delas apontam para a realização de transmissões no mês de fevereiro de 1923, portanto antes das da Rádio Sociedade do Rio de Janeiro. Conforme o Diário de Pernambuco (FAMÍLIA..., 1973, p. 13), Moreira Pinto desembarca em 1922, trazendo na bagagem "um transmissor Levy de 20W e um receptor Crowsley", equipamento que vai resultar em "uma pobre, mas engenhosa, adaptação", tendo como "microfone, uma lata de doce, curvada em forma de cone". Há aqui algumas imprecisões. A francesa Établissements Radio L. L., fundada em 1917 por Lucien Lévy, só começa a fabricar transmissores em 1923 (100 ANS..., [200-?]). Já o receptor provavelmente foi grafado de forma equivocada. Deve se tratar de um Harko, o primeiro rádio de preço acessivel - US\$20, logo reduzidos para US\$ 9 - produzido em larga escala e desenvolvido por iniciativa de Powel Crosley Jr. - portanto, sem o "w" -, "o Henry Ford do rádio" (LIGHTY, 2004, v. 1, p. 420) em uma comparação com o industrial que, com seu Modelo T, popularizou o automóvel.

Luiz Maranhão Filho²3 (informação verbal), principal defensor do pioneirismo do Rádio Clube, apresenta versão algo diversa, mas também aponta a importância de Dubeux Pinto nas transmissões de fevereiro de 1923

[...] localizaram nos Correios e Telégrafos um transmissor de telegrafia do fabricante Lucien Levy, de Paris, e esse transmissor estava desativado. Então, eles começaram a mexer nesse transmissor [...] para fazer uma adaptação para fonia. Conta-se que esse rapaz [Dubeux Pinto]

\footnotetext{
20 Método que utiliza o radiogoniômetro: "Aparelho receptor de ondas eletromagnéticas, que permite determinar a direção em que se encontra o posto que as emite" (LELLO, [193-], v. 2, p. 821).

${ }_{21}$ Bairro da Zona Norte de Recife.

22 Referência à cidade de Jaboatão dos Guararapes, município vizinho de Recife.

23 Entrevista de Luiz Maranhão Filho concedida ao pesquisador Luiz Ferraretto, por telefone, em 8 de março de 2017.
} 
era tão curioso que pegou uma lata de goiabada, fez uma série de furinhos e adaptou para microfone movido a carvão magnético e esse microfone tinha uma ressonância tão grande que a pessoa tinha que falar numa distância de cinco metros para não dar o eco, a repetição.

A respeito de Oscar Moreira Pinto, descreve:

Fora das atividades marítimas, o ex-telegrafista não buscou, então, um passatempo, um clube de radiófilos. O que ele queria eram raizes; tanto que o transmissor adaptado já foi montado num casarão existente na rua Cruz Cabugá, número 349, endereço que a emissora de Oscar Moreira Pinto conservaria até os nossos dias. Foi neste endereço, o palco das primeiras experiências com o Lévy, confirmadas em depoimento do irmão de Oscar, Arnaldo Moreira Pinto, feito no Museu da Imagem e Som de Pernambuco. O som foi captado no portão, em fevereiro de 1923 (MARANHÃO FILHO, 1991, p. 9).

Versão semelhante é apresentada por Jota Alcides (1997, p. 53), dando como fonte também Arnaldo Moreira Pinto, mas identificando o equipamento como um Westinghouse, de alcance maior, e afirmando que, assim, "foi possivel ser ouvido o som da emissora pioneira no centro e alguns subúrbios da capital pernambucana". Pode-se tratar de uma confusão com irradiações posteriores relacionadas com a reorganização do Rádio Clube em 17 de outubro daquele ano. Observe-se o que registra o Diário de Pernambuco (RÁDIO..., 1923, p. 3) sobre a reunião realizada em 6 de novembro, na qual se dá a aprovação dos novos estatutos da entidade:

Encerrada a sessão foram realizadas demonstrações práticas de radiotelefonia com os seguintes aparelhos: um da casa Telefunken, um fabricado em Pernambuco pelo sr. Tito Xavier, outro pelo sr. Manoel Roberto da Costa e um outro tipo Westinghouse e fabricado também em Pernambuco, pelos irmãos Gatis.

Já Renato Phaelante da Câmara (1994, p. 28) observa:

Há notícias de que, apesar das dificuldades, no início dos anos 20, já na fase de rádio experimental, transmitem-se óperas, suites, obras clássicas em geral, tudo isso feito através de discos emprestados pelos associados, servindo de programas eventuais para os novos adeptos que crescem em número, gradativamente, com seus receptores de rádio galena ${ }^{24}$, acompanhados de fone de ouvidos.

De fato, antes da reorganização, o Jornal Pequeno (RÁDIO..., 1923, p. 3) chega a registrar:

O Rádio Clube previne aos senhores amadores que diligencia para irradiar hoje à noite o espetáculo do Teatro Santa Isabel. Caso não seja possivel, fará, como de costume, irradiar peças de vitrola.

O Rádio Clube tem usado dois comprimentos de onda, 300 e 800 metros.

Mesmo reorganizado, o pioneiro capítulo pernambucano do desenvolvimento da radiocultura ainda vai enfrentar uma série de dificuldades até o início da década de 1930. Conforme registra o Diário de Pernambuco, o Rádio Clube chega a contar apenas com 93 associados (CAPANEMA, 1929, p. 4), estando à beira "de sucumbir por inanição" (RADIOELETRICIDADE, 1929, p. 3). De acordo com Jota Alcides (1997, p. 54), usava, na época, o prefixo SQ1-C, dado pela Confederação Sul-americana de Radiodifusão, trocado para PRA-P, em 1931, e para PRA-8, cinco anos depois. Com a publicidade regulamentada pelo Governo Federal e incorporado aos Diários e Emissoras Associados, de Francisco de Assis Chateaubriand Bandeira de Melo, o Rádio Clube completaria a sua transição para a Rádio Clube, de entidade de amadores transformando-se em empresa. Já então, o rádio como meio de comunicação de massa era uma instituição social, dependendo da região, consolidada ou em vias de consolidação.

\section{Considerações finais}

Embora subsistam incongruências a respeito das irradiações iniciais do Rádio Clube de Pernambuco, há indícios suficientes que apontam para esta sociedade de amadores do sem fio como a primeira a irradiar som via ondas eletromagnéticas de um ponto de transmissão para vários de recepção. Como descrito, existe certo grau de divergência em relação às informações

24 Galena é a denominação do sulfeto de chumbo em estado natural. Por extensão, o termo identifica um tipo de receptor de rádio fabricado, em geral, de forma caseira e dependente de uma escuta com fones de ouvido. 
sobre as irradiações iniciais, prejudicadas pelo próprio fato dessas, em vários momentos, serem consideradas ilegais. Destaque-se, inclusive, os registros existentes sobre a diversidade de equipamentos que podem ter sido empregados: do uso de um instrumental fabricado originalmente por empresas estrangeiras ao de estruturas montadas em Recife com peças vindas do exterior, passando mesmo por adaptações criativas e até inusitadas dessas - como no caso da lata de goiabada transformada em base para um microfone por Oscar Dubeux Pinto.

Não são dados, de fato, totalmente conclusivos. No entanto, condicionar o rádio à tecnologia soa algo reducionista, ainda mais em pleno século 21, quando o seu conceito abandonou uma descrição meramente tecnológica do tipo: "Meio de comunicação que utiliza emissões de ondas eletromagnéticas para transmitir a distância mensagens sonoras destinadas a audiências numerosas" (FERRARETTO, 2007, p. 23). Melhor descrevê-lo em relação à instituição social construida coletivamente como na proposição de Eduardo Meditsch (2010, p. 204) citada inicialmente.

É de se perguntar, então, quando essa instituição social particular - o rádio - começou a se desenvolver como tal. Para além da questão tecnológica óbvia a respeito de quem irradiou antes, acredita-se que se tenha, em uma aproximação com o conceito de Meditsch, descrito aqui o início da radiocultura, aquele processo a transformar a telegrafia e a telefonia sem fio ambas ponto-ponto - em uma nova instituição social caracterizada por uma forma particular de consumo cultural de um conteúdo sonoro transmitido na forma ponto-massa. Neste sentido, sem dúvida, trata-se de uma transformação que, no caso brasileiro, inicia-se em meados da década de 1910 na cidade do Recife, tendo por eixo a fundação de uma entidade de entusiastas em 6 de abril de 1919 - o Rádio Clube de Pernambuco -, permitindo afirmar que, lá, começou o rádio como meio de comunicação massivo no país.

\section{Referências}

100 ANS de Radio. Biographies - Lucien Levy. [s.l.], [200-?]. Disponivel em: http://100ansderadio.free.fr/ Biographies/Levy_Lucien.html. Acesso em: 19 set. 2020.

A RADIOTELEFONIA na Marinha. A Noite, Rio de Janeiro, 20 mar. 1920. p. 3.

A RADIOTELEFONIA na Marinha. Fon-fon, Rio de Janeiro, 10 abr. 1920. p. 1-3.

ATELEFONIA sem fios. A Provincia, Recife, 5jul. 1914. p. 9.

A TELEFONIA sem fios na Marinha. A Noite, Rio de Janeiro, 9 fev. 1920. p. 3

ALCIDES, J. PRA-8 - 0 rádio no Brasil. Brasilia: Fatorama, 1997.

ASSOCIAÇÃO BRASILEIRA DE PESQUISADORES DE HISTÓRIA DA MÍDIA. Carta de Natal. Natal, 20 jun. 2019. Disponivel em: https://plone.ufrgs.br/alcar/jornal-alcar/jornal-alcar-no-73-julho-2020/carta-de-natal. Acesso em 14 set. 2020

CÂMARA, Renato Phaelante da. Fragmentos da história do Rádio Clube de Pernambuco. 2.ed. Recife Cepe, 1998.

CAMELO, Antônio. Atuando desde 1919, a Rádio Clube de Pernambuco é pioneira no Brasil. Diário de Pernambuco, Recife, 19 jul. 1984. Rádio Clube, 65 anos, 100 quilowatts, p. 2-4.

CAPANEMA, Oscar. de Ipseudônimo de Oscar Moreira Pinto]. Radioeletricidade. Diário de Pernambuco, Recife, 6 jun. 1929. p. 4.

CONFERÊNCIAS. Jornal do Recife, Recife, 16 abr. 1914. p. 11.

CONVOCAÇÃO. Rádio Clube de Pernambuco. Diário de Pernambuco, Recife, 11 out. 1923. p. 6.

DIÁRIO Social. Diário de Pernambuco, Recife, 18 nov. 1914. p. 5.

DICIONÁRIO Prático llustrado/ Novo Dicionário Enciclopédico Luso-Brasileiro. Lisboa, 1910.

ENGENHEIRO Tito Xavier. Jornal do Recife, Recife, 2 out. 1918. p. 1.

FAMÍLIA Associada presta homenagem. Diário de Pernambuco, Recife, 31 mar. 1973. p. 13.

FEDERICO, Maria Elvira Bonavita. História da comunicação: rádio e TV no Brasil. Petrópolis: Vozes, 1982.

FERRARETTO, Luiz Artur. Rádio - O veículo, a história e a técnica. 3. ed. Porto Alegre: Doravante, 2007.

FERRARETTO, Luiz Artur. Uma proposta de periodização para a história do rádio no Brasil. Eptic - Revista de Economia Politica das Tecnologias da Informação e Comunicação, Aracaju: Observatório de Economia e Comunicação da Universidade Federal de Sergipe, v. 14, n. 2 , maio/ago. 2012. Disponivel em: https://seer.ufs.br/index. php/eptic/article/view/11508. Acesso em: 25 set. 2020. 
FERRARETTO, Luiz Artur. Roberto Landell de Moura, o pioneiro brasileiro das telecomunicações. In: KLÖCKNER, Luciano; CACHAFEIRO, Manolo Silveiro (org.). Por que o padre Roberto Landell de Moura foi inovador? Porto Alegre: Editora da PUCRS/ Prefeitura de Porto Alegre, 2012. p. 38-54. Disponivel em: http:// ebooks.pucrs.br/edipucrs/Ebooks/Web/978-85-3970226-8/pages/v2.pdf. Acesso em: 25 set. 2020.

FERRARETTO, Luiz Artur. De 1919 a 1923, os primeiros momentos do rádio no Brasil. Revista Brasileira de História da Mídia, São Paulo, ano 2, v. 3, n. 1, p. 11-20, jan./jun. 2013 Disponivel em: https://revistas.ufpi.br/ index.php/rbhm/article/view/3961/2299. Acesso em: 25 set. 2020.

FERRARETTO, Luiz Artur. O rádio antes do rádio: o Brasil como mercado para uma nascente indústria eletroeletrônica nas décadas de 1910 e 1920. Conexão - Comunicação e Cultura, Caxias do Sul, v. 17, n. 33. p. 145-164, jan./jun. 2018. Disponivel em: http:// www.ucs.br/etc/revistas/index.php/conexao/article/ view/5758/3375. Acesso em: 25 set. 2020.

LACOMBE, Carlos. KDKA em São Paulo. Rádio, Rio de Janeiro, ano 1, n. 8, p. 7-8, fev. 1924.

LIGHTY, L. W. Crosley, Powel 1886-1961. In: STERLING, C. H. (ed.). The Museum of Broadcast Communications encyclopedia of radio. Nova lorque: Taylor and Francis Group, 2004. v. 1, p. 420-422.

LOGO que obtenha... Jornal Pequeno, Recife, 1 jul. 1913. p. 3

MARANHÃO FILHO, Luiz. Memória do rádio. Recife: Jangada, 1991.

MARANHÃO, Zilde. Música, ruido e chiado confundiam-se nas transmissões da década de vinte. Diário de Pernambuco, Recife, 19 jul. 1984. Rádio Clube, 65 anos, 100 quilowatts, p. 5 .

MEDITSCH, Eduardo. A informação sonora na webemergência: sobre as possibilidades de um radiojornalismo digital na mídia e pós-mídia. In: MAGNONI, Antônio Francisco; CARVALHO, Juliano Francisco de (org.). O novo rádio: cenários da radiodifusão na era digital. São Paulo: Senac, 2010. p. 203-238.

MIESSNER, Benjamin F. Radiodynamics: the wireless control of torpedoes and others mechanisms. Nova Iorque: D. Van Nostrand Company, 1916.

MELO, Mário. A telegrafia sem fios no Brasil. Jornal Pequeno, Recife, 1 jan. 1910. p. 1.

NAS EXPERIÊNCIAS de radiotelefonia... Jornal do Recife, Recife, 19 abr. 1911. p. 1.

O GRANDE Marconi esteve algumas horas no Rio Jornal Pequeno, Recife, 12 out. 1910. p. 1.

RADIO. In: OXFORD English Dictionary. 2. ed. Oxford: Oxford University Press, 2009. CD-ROM.

RADIOGONIÔMETRO. In: LELLO Universal - Novo Dicionário Enciclopédico Luso-Brasileiro. Porto: Lello, [193-]. 2 v.

PEREIRA, Augusto. Brazilian radio club. Radio Amateur News, Nova lorque, ano 1, v. 1, n. 2, p. 69, ago. 1919.
PEREIRA, Augusto. Brazil radio club. Radio Amateur News, Nova lorque, ano 1, v. 1, n. 3, p. 126, set. 1919.

PINTO, Humberto Sodré. Subsídios para a história do rádio em Pernambuco. In: MORAIS, Osvando J. de (org.). Comunicações \& Problemas - Luiz Beltrão - Parte 1. São Paulo: Sociedade Brasileira de Estudos Interdisciplinares da Comunicação, 2013. p. 202-231.

PINTO, Oscar Dubeux. Rádio Clube de Pernambuco Notas sobre sua história. Rio de Janeiro: abr. 1984. Texto fornecido pelo autor à Fundação Joaquim Nabuco, de Recife (PE).

PORTO DO RECIFE S.A. História. Recife, [200-?]. Disponivel em: http://wwww.portodorecife.pe.gov.br/historia. php. Acesso em: 14 set. 2020.

PUBLICAÇÕES. A Província, Recife, 20 maio 1910. p. 1.

PUBLICAÇÕES. A Província, Recife, 15 maio 1915. p. 1.

RÁDIO Clube. Jornal Pequeno, Recife, 5 abr. 1919. p. 3.

RÁDIO CLUBE DE PERNAMBUCO. Estatutos e regulamento das estações. Recife, 1919.

RÁDIO Clube de Pernambuco. Diário de Pernambuco, Recife, 18 out. 1923, p. 1

RÁDIO Clube de Pernambuco. Diário de Pernambuco Recife, 7 nov. 1923, p. 3

RÁDIO Clube de Pernambuco. Jornal Pequeno, Recife, 10 out. 1923. p. 3

RÁDIO Clube de Pernambuco. Jornal Pequeno, Recife, 2 maio 1925. p. 3.

RADIOELETRICIDADE. Diário de Pernambuco, Recife, 7 jun. 1929. p. 3.

RADIOTELEFONIA. Diário da Manhã, Vitória, 5 mar 1920. p. 3.

RADIOTELEFONIA. Diário de Pernambuco, Recife, 28 maio 1925. p. 2.

RADIOTELEFONIA. Diário de Pernambuco, Recife, 19 set. 1925. p. 1.

RADIOTELEGRAFIA. A Província, Recife, 20 abr. 1915. p. 1.

SILVESTRIN, C. B.; NÖLL, G. (org.); JACKS, N. (coord.) Capitais brasileiras: dados históricos, demográficos, culturais e midiáticos. Curitiba: Appris, 2016.

SLAVIERO, Daniel Pimentel. Os 90 anos do rádio brasileiro. Folha de S.Paulo, São Paulo, 25 set. 2012. p. A3.

THE AMATEUR station owned and... Radio Amateur News, Nova lorque, ano 6, v. 6, n. 5, p. 680, nov. 1924.

THE RADIO League of America. The Electrical Experimenter, Nova lorque, v. 3, n. 8, p. 381-384, dez. 1915.

TORQUET, Charles. A telegrafia sem fios marcha dia a dia em admiráveis progressos. O comendador Marconi, que tanto trabalhou pela sua criação e propagação, acaba de praticar a bordo de um paquete uma série de experiências extremamente importantes. Jornal Pequeno, Recife, 21 jan. 1911. p. 3. 
WIRELESS. In: OXFORD ENGLISH DICTIONARY. 2. ed. Oxford: Oxford University Press, 2009. CD-ROM.

\section{Luiz Artur Ferraretto}

Doutor em Comunicação e Informação pela Universidade Federal do Rio Grande do Sul (UFRGS), em Porto Alegre, RS, Brasil; professor no curso de Jornalismo e no Programa de Pós-graduação em Comunicação da UFRGS.

\section{Endereço para correspondência}

Luiz Artur Ferraretto

Universidade Federal do Rio Grande do Sul

Faculdade de Biblioteconomia e Comunicação

Rua Ramiro Barcelos, 2705

Campus Saúde, 90035-007

Porto Alegre, RS, Brasil

Os textos deste artigo foram revisados pela Poá Comunicação e submetidos para validação do autor antes da publicação. 